\title{
Microarray-based long oligonucleotides probe designed for Brucella Spp. detection and identification of antibiotic susceptibility pattern
}

\author{
Zahra Khazaei ${ }^{1}$, Ali Najafi ${ }^{2}$, Vahhab Piranfar ${ }^{3}$, Reza Mirnejad ${ }^{4}$
}

${ }^{1}$ M.Sc. of Biotechnology, Molecular Biology Research Center, Baqiyatallah University of Medical Sciences, Tehran, Iran

${ }^{2}$ Ph.D. of Bioinformatic, Assistance Professor, Molecular Biology Research Center, Baqiyatallah University of Medical Sciences, Tehran, Iran

${ }^{3}$ M.Sc. of Microbiology, Department of Biology, Tonekabon Branch, Islamic Azad University, Tonekabon, Iran

${ }^{4}$ Ph.D. of Medical Bacteriology, Associate Professor, Molecular Biology Research Centre, Baqiyatallah University of Medical Sciences Tehran. Iran

\section{Type of article: Original}

\begin{abstract}
Brucella spp. is a common zoonotic infection referred to as Brucellosis, and it is a serious public health problem around the world. There are currently six classical species (pathogenic species in both animals and humans) within the genus Brucella. The ability and practicality facilitated by a microarray experiment help us to recognize Brucella spp. and its antibiotic resistant gene. Rapid phenotypic determination of antibiotic resistance is not possible by disk diffusion methods. Thus, evaluating antibiotics pattern and Brucella detection appear necessary technique by molecular methods in brucellosis. So, the aim of this study was to design a microarray long oligonucleotides probe and primer for the complete diagnosis of Brucella spp. and obtaining genetic profiles for antibiotic resistance in bacteria at the same time. In this study, we designed 16 antibiotic-resistant gene solidphase primers with similar melting temperatures of $60^{\circ} \mathrm{C}$ and 16 long oligonucleotide probes. These primers and probes can identify tetracycline-, chloramphenicol-, and aminoglycoside-resistant genes, respectively. The design of microarray probes is a versatile process that be done in a wide range of selections. Since the long oligo microarray probes are the best choices for specific diagnosis and definite treatment, this group of probes was designed in the present survey.
\end{abstract}

Keywords: Brucella, detection, antibiotic susceptibility, Microarray

\section{Introduction}

Brucella spp. is a common zoonotic infection referred to as Brucellosis. Non-motile, non-spore-forming, gramnegative coccobacilli bacteria are a serious public health problem around the world, especially in developing countries $(1,2)$. Brucellosis is an endemic disease in the Middle East, the Mediterranean countries, and East Asia (1, 3). Annually, 10,000 people are infected with this disease in Turkey (2). The World Health Organization (WHO) has reported about that every year, 500,000 new cases of brucellosis were diagnosed in the above regions $(4,5)$. This inflicts irreparable economic damage on the health systems of these countries. Due to the implementation of health programs, the prevalence of brucellosis has decreased sharply in many developed countries $(6,7)$. However, brucellosis is an endemic disease in Southeast European countries, such as Croatia and Macedonia (8). There are currently six classical species (pathogenic species of both animals and human) within the genus Brucella, namely, Brucella abortus (preferred hosts are cattle and buffalos), Brucella melitensis (goats, sheep, and camels), Brucella ovis (sheep), Brucella canis (dogs), Brucella suis (swine, horses, cattle, wild hares, wild boars), and Brucella neotomae (desert wood rats) (9). Brucella suis and Brucella neotomae are endemic to Southeast Europe. This study designed primers and probes for all six classical species. Following the recommendations of the WHO published in

\section{Corresponding author:}

Dr. Reza Mirnejad, Molecular Biology Research Centre, Baqiyatallah University of Medical Sciences Tehran. Iran. Tel: +98. 2182482554, Email: rmirnejad@bmsu.ac.ir

Received: January 08, 2016, Accepted: March 30, 2016, Published: April 2016

iThenticate screening: March 05, 2016, English editing: April 04, 2016, Quality control: April 10, 2016

(C) 2016 The Authors. This is an open access article under the terms of the Creative Commons Attribution-NonCommercialNoDerivs License, which permits use and distribution in any medium, provided the original work is properly cited, the use is non-commercial and no modifications or adaptations are made. 
1989, the gold standard for the treatment of brucellosis is combinatorial treatment, i.e., doxycycline-Rifampin are used for six weeks, or doxycycline is taken for six weeks together with streptomycin for 2-3 weeks (10). These drugs have serious side effects on patients (11-13). Moreover, some studies have shown that recurrence rates of 5 $10 \%$ occur due to inappropriate treatment $(14,15)$. So, these factors, such as the high rate of recurrence, resistance to rifampin (because tuberculosis is endemic in some parts of countries), and toxic side effects (damage to the middle ear, nephrotoxicity resulting from the use of streptomycin), have led to trying new treatment options for brucellosis. Fluoroquinolones and macrolides, gentamicin, ciprofloxacin, cotrimexazole, tetracycline, tigecycline, and erythromycin are being used as new anti-microbial agents $(16,17)$. A new report has shown resistance to all of these antibiotics. So, the best anti-microbial pattern recommended for the treatment of human brucellosis has become important. Recently, microarray hybridization of pre-amplified deoxyribonucleic acid sequences to arrayed species-specific oligonucleotides has been used as a fast technique for the detection and identification of bacterium (18). Microarrays are powerful techniques for the rapid and parallel detection of microorganisms' genomes in deferential samples, such as blood. PCR amplification products (PCR results) could be analyzed in comparison by mistreatment high-density oligonucleotide microarrays. Powerful analytical devices having hundreds or thousands of probes connected to solid support (19). This ability and practicality facilitate the recognition of Brucella antibiotic resistance genes, because gold standard detection (Brucella culture) need long time (1-2 weeks) (20). Therefore, rapid phenotypic determination of antibiotic susceptibility pattern is not possible by disk diffusion methods (21). Thus, evaluating antibiotics' patterns and Brucella detection appear to be necessary techniques by molecular methods in brucellosis. So, the aims of this study were to design long oligo microarray probes for the complete diagnosis of Brucella spp. and to obtain genetic profiles for antibiotic resistance in bacteria at the same time.

\section{Material and Methods}

This study designed one pair Primer for detecting all 6 classical species. Complete genome sequence of six Brucella spp. studied via the national center for biotechnology information (NCBI) Genome database (http://www.ncbi.nlm.nih.gov/genome) and the RefSeq complete genome regarding the six strains were detected throughout the related files of GeneMarkS, version 2.5M. Then, for each RefSeq, a complete genome was retrieved from NCBI Nucleotide database (http://www.ncbi.nlm.nih.gov/nuccore) to study the sequence length and total genes involved within a complete genome. The data are shown in Table 1. We applied complete genome sequence of six Brucella spp. as inclusion/exclusion criteria to identify and design primers and microarray-based long oligonucleotides probes.

Table 1. Six reported identified classical Brucella strain genomes via NCBI Genome database

\begin{tabular}{|l|l|l|l|}
\hline Brucella strains & Complete genome/RefSeq accessio no. & Size $(\mathrm{Mb})$ & Total genes \\
\hline Brucella abortus 2308 & NC_007618.1 & 2.12 & 2,085 \\
\hline Brucella melitensis ATCC 23457 & NC_012441.1 & 2.13 & 2,056 \\
\hline Brucella ovis & NC_009505.1 & 2.11 & 2,063 \\
\hline Brucella neotomae 5K33 & NZ_ACEH00000000.1 & 3.3 & 3,129 \\
\hline Brucella canis ATCC 23365 & NC_010103.1 & 2.11 & 2,018 \\
\hline Brucella suis ATCC 23445 & NC_010169.1 & 1.92 & 1,844 \\
\hline
\end{tabular}

The best server to show clear similarities among different Brucella spp. is the GViewer Server (22). Furthermore, NCBI guarantees appropriate support for GenBank data and BLAST tools. Last, the PanSeq server is used for appropriate result of genomic unique regions. Therefore, the primers and probes were designed based on AleleID 7.83 (Premier Biosoft, USA) for the detection of Brucella species antibiotics resistance gene. This study designed antibiotics resistance gene solid-phase primers with similar melting temperatures of $60{ }^{\circ} \mathrm{C}$ in Table 2 . We designed a long oligonucleotide probe, as described in Table 3 . To design the probe, lengths of 40-53 bp were selected, and the other defaults were in accordance with the software choice. The final probe was extracted for further analyses. The specificity of Primer and microarray probes had been approved by The Basic Local Alignment Search Tool (Blast, NCBI, USA). For Chloramphenicol antibiotics resistance gene, catB ${ }^{+}$reported as Chloramphenicol Resistance gene. The relation between increased drug resistance to chloramphenicol and genes was unknown. But Shaw et al. published a study in Nature and showed the catB ${ }^{+}$gene as a chloramphenicol-resistant gene (23). Several tetracycline-resistant determinants currently are used in molecular biology. The most encountered are the tet family

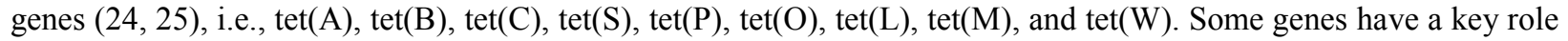
to resist to tobramycin and amikacin (Tob. Amk), such as aac(6')-Ib $(26,27)$. In addition, aac(3)-Ia and aac(6')-Ibcr4 genes represent gentamicin and kanamycin, respectively $(28,29)$. Moreover, ant(3")-Ia was introduced as a 
spectinomycin-resistant gene (30). The gene sequence studied via the NCBI Genome database (http://www.ncbi.nlm.nih.gov/genome) was used to design the primers and probes. The provided microarray probes were rechecked by NCBI BLAST tool software and the physical-chemical and structural characteristics, such as $\Delta \mathrm{G}$, $\mathrm{Tm}, \Delta \mathrm{H}$, and hairpins of designing microarray probes, were tested via the online tool of oligoanalyzer 3.1 $(<$ https://eu.idtdna.com/calc/analyzer $>)$. Other default parameters were performed in this study, including target type: DNA, oligo Conc: $0.25 \mu \mathrm{M}, \mathrm{Na}+$ Concentration: $50 \mathrm{Mm}$, Nucleotide type: DNA, Sequence type: linear, Temperature: $25{ }^{\circ} \mathrm{C}$, Max foldings: 25, Suboptimality: 50\%, Start position: 0 and Stop position: 0. Finally, the accurate and standard long oligonocleotides probes were selected for use in designing a diagnostic DNA microarray chip.

Table 2. Primer oligonucleotides sequence for detection Brucella spp. and antibiotics resistance gene. (Sorted by amplification target length)

\begin{tabular}{|c|c|c|}
\hline Target & Primers & Length \\
\hline \multirow[t]{2}{*}{ Brucella spp. } & $\begin{array}{l}\text { 5'GCGTTGGAGGCGACATTGACA3' } \\
\text { 5'AGGCTGGCGAGGCGGATG3' }\end{array}$ & 286 \\
\hline & Tetracycline Resistance Genes & \\
\hline $\operatorname{tet}(W)$ & $\begin{array}{l}\text { 5'ACGGCTGCTGGACGCTCTT3' } \\
\text { 5'ATGGTGTGGCTGGCTGCTTTG3' }\end{array}$ & 219 \\
\hline $\operatorname{tet}(L)$ & $\begin{array}{l}\text { 5'CCACCTGCGAGTACAAACTGGG3' } \\
\text { 5'ATCGCTGGACCGACTCCTTCTC3' }\end{array}$ & 335 \\
\hline $\operatorname{tet}(P)$ & $\begin{array}{l}\text { 5'GCTCCCTCTGCTGCAAACAACT3' } \\
\text { 5'TCCCAACGGAAGCGGTGATACA3' }\end{array}$ & 340 \\
\hline $\operatorname{tet}(S)$ & $\begin{array}{l}\text { 5'CCCTGTCAGTACGCCAGCAGAT3' } \\
\text { 5'TTGGACGACGTGGTTGGAAAGC3' }\end{array}$ & 350 \\
\hline $\operatorname{tet}(B)$ & $\begin{array}{l}\text { 5'ATCGGGTCCCTGGTAGCAATGG3' } \\
\text { 5'AGTCCTCCGCAAAGGGTTCCAA3' }\end{array}$ & 371 \\
\hline $\operatorname{tet}(A)$ & $\begin{array}{l}\text { 5'TCGTCGCCGCCCTGATGG3' } \\
\text { 5'GCCGCATAGATCGCCGTGAAG3' }\end{array}$ & 451 \\
\hline $\operatorname{tet}(C)$ & $\begin{array}{l}\text { 5'CGCAGTCAGGCACCGTGTATG3' } \\
\text { 5'CGCCGCCGCAAGGAATGG3' }\end{array}$ & 519 \\
\hline $\operatorname{tet}(O)$ & $\begin{array}{l}\text { 5'TTCTGGGCTTCTGTCGGGTTGT3' } \\
\text { 5'CTATTCGGGCGGCGGGGTT3' }\end{array}$ & 557 \\
\hline $\operatorname{tet}(M)$ & $\begin{array}{l}\text { 5'CGAGGTCCGTCTGAACTTTGCG3' } \\
\text { 5'GCGGCACTTCGATGTGAATGGT3' }\end{array}$ & 583 \\
\hline & Chloramphenicol Resistance Gene & \\
\hline catB & $\begin{array}{l}\text { 5'AGCCTCTCAGCGAACAGGTCAA3' } \\
\text { 5'AGTCCCACCACGCCATTTCCA3' }\end{array}$ & 507 \\
\hline & Aminoglycoside Resistance Genes & \\
\hline Aac & $\begin{array}{l}\text { 5'TGGAGCACTGGCGCGGATT3' } \\
\text { 5'GAAAACCACGGGCGAACTGTCA3' }\end{array}$ & 200 \\
\hline$a a c\left(6^{\prime}\right)-I b$ & $\begin{array}{l}\text { 5'AGAAGAAGCACGCCCGACACT3' } \\
\text { 5'GTTCCCAAGCCTTTGCCCAGTT3' }\end{array}$ & 237 \\
\hline$a a c(3)-I a$ & $\begin{array}{l}\text { 5'GAGTTCGGAGACGTAGCCACCT3' } \\
\text { 5'ATAGAGAGCCACTGCGGGATCG3' }\end{array}$ & 324 \\
\hline$a a c\left(6^{\prime}\right)-I b-c r 4$ & $\begin{array}{l}\text { 5'CAACAGCACCGATTCCGTCACA3' } \\
\text { 5'GTTCCCAAGCCTTTGCCCAGTT3' }\end{array}$ & 339 \\
\hline $\operatorname{ant}\left(3{ }^{\prime \prime}\right)-I a$ & $\begin{array}{l}\text { 5'TCAGAGGTAGTTGGCGTCATCG3' } \\
\text { 5'GCGGCGAGTTCCATAGCGTTA3' }\end{array}$ & 490 \\
\hline
\end{tabular}

\section{Results and discussion}

This article designed 16 primer oligonucleotides sequence with the same temperature program for use DNA microarray detection (Table 2). Therefore, we designed 16 long oligonucleotides probes for DNA microarray methods (Table 3). 
There has been extensive scientific research that has shown a wide range of zoonotic infections, which are caused by different strains of Brucella (31-34). The identification of these bacteria can be very critical in the medical society (35). Because of some antibiotic-resistant genes, the prevalence of Brucellosis is increasing, and, as a result, it is necessary to develop a rapid identification technique that can replace culture and biochemical tests. In this study, by using suitable primers and the microarray method, some resistant antibiotics were identified among Brucella spp. in a short time.

Table 3. Microarray DNA probe oligonucleotides for detection Brucella spp. and antibiotics resistance genes with same annealing temperature

\begin{tabular}{|l|l|l|}
\hline Target & Probe & Length \\
\hline Brucella spp. & 5'GTTCTGCTTGTACTGGATGGAATAGACATTGTCGTAGCCACCTTCTT3' & 47 \\
\hline & 'tetracycline Resistance Genes & \\
\hline tet(A) & 5'CCTCCTCTTCACGGCGATCTATGCGGCTTCTATAACAACG3' & 40 \\
\hline tet(B) & 5''GATCATTGGATTTGTTGGACACTCTTTCTTTCCTATTCTCATTCTAGCCCG3' & 52 \\
\hline tet(C) & 5'CACAGTTAAATTGCTAACGCAGTCAGGCACCGTGTATGAAATCTAACAATG3' & 51 \\
\hline tet(S) & 5'AGTAGCGGAGCAATTAAAGAGTTAGGAAGTGTAGATAGCGGTACAACGAA3' & 50 \\
\hline tet(P) & 5'ATAACAGTGGAGCGATTACAGAATTAGGAAGCGTGGACAAAGGTACAAC3' & 49 \\
\hline tet(O) & 5'AACCAGGGAGCGTAGATAAAGGCACAACAAGGACAGATACAATGAAT3' & 47 \\
\hline tet(L) & 5'CGGCTACATTGGTGGGATACTTGTTGATAGAAGAGGTCCTTTATACGTGTTAA3' & 53 \\
\hline tet(M) & 5'ATAACAGTGGAGCGATTACAGAATTAGGAAGCGTGGACAAAGGTACAAC3' & 49 \\
\hline tet(W) & 5'TGAAATTGTTATCCTTCCCAGCGACAGCGTGAGGTTAAACGATGTATTA3' & 49 \\
\hline & Chloramphenicol Resistance Gene & \\
\hline catB & 5'GATACCGTGATTGGAAATGATGTGTGGATTGGTTCAGAAGCGATGATTT3' & 49 \\
\hline & Aminoglycoside Resistance Genes & \\
\hline aac(3)-Ia & 5'CAAGCAGATTACGGTGACGATCCCGCAGTGGCTCTCTATACAAAGTT3' & 47 \\
\hline aac(6')-Ib & 5'TGAGTATTCAACATTTCCAAACAAAGTTAGGCATCACAAAGTACAGCATCGT3' & 52 \\
\hline aac & 5'CAATTTCACAGAAAGTTCACCTGGCGTTAGGATTTGAGGAAACAGAGC3' & 48 \\
\hline ant(3')-Ia & 5'TCATACTTGAAGCTAGGCAGGCTTATCTTGGACAAGAAGATCGCTTG3' & 47 \\
\hline aac(6')-Ib-cr4 & 5'TGGAAATACTGACAAGTTAGGCATCACAAAGTACAGCATCGTGACCA3' & 47 \\
\hline
\end{tabular}

It was observed that some species that carried the tet family gene showed resistance to tetracycline although the majority of spp. had the tet + gene, which means that there was a high level of tectracycline resistance in this period. In fact, this kind of resistance causes bacteria to acquire new genes, which are responsible to code a protein that protects bacterial ribosomes from the action of tetracyclines. However, resistance to aminoglycoside was detected by probes that were designed based on $\operatorname{acc}(3)$, acc(6), and ant genes. These aminoglycoside resistance genes existing in the most of Brucella spp. represent High Level of Aminoglycoside Resistance (HLAR). Regarding the mechanism of chloramphenicol resistance, there is its enzymatic inactivation by acetylation mainly via acetyltransferases or, in some cases, by chloramphenicol phosphotransferases.

In the present study, Brucella neotomae 5K33 included the highest number of genes (3129 genes) and nucleotide sequences $(3.3 \mathrm{Mb})$ in Table 1, was selected as standard sample for designing long oligonocleotides microarray probes. So, an accurate, rapid, sensitive, and specific diagnostic tool results a definite treatment that may lead to the reduction of unnecessary costs for public health around the world. One of the most efficient molecular diagnostic technology is the DNA microarray, which makes a reliable diagnosis regarding microbial agents of various infectious diseases at the same time (1-5). DNA microarray technology includes several stages, the most important of which is designing probes. Regarding this stage, scientists can use a wide range of databases, tools, and servers for microarray probes. This technology is a valuable method to use the obtained information for AlleleID tool to retrieve invaluable raw data in the form of designing microarray probes. By comparing the genome sequence of six Brucella species, our study could not find the specific unique areas for long probe designing. More analysis showed 
that Brucella spp. had elements that can move between genomes. So, the microarray technique could not differentiate between Brucella spp.

Designing microarray probes is a versatile process that can be done in a wide range of selections. Since, the long oligo microarray probes are the best choices for specific diagnosis and definite treatment, this group of probes was designed in the present survey. Moreover, probes can be designed in two forms, i.e., general and specific. In the past, microbial resistance was a complicated issue in hospitals and health centers throughout the world, but the microarray diagnostic method can be a solution in this matter, because today's microarray probes are designed for normal virulence or multi-drug resistance genes (3641).

\section{Acknowledgments:}

This article was derived from Ms. Zahra Khazai's M.Sc. thesis in Biology Research Center, Baqiyatallah University of Medical Sciences with grant number: BMSU93061207.

\section{Conflict of Interest:}

There is no conflict of interest to be declared.

\section{Authors' contributions:}

All authors contributed to this project and article equally. All authors read and approved the final manuscript.

\section{References}

1) Rubach MP, Halliday JE, Cleaveland S, Crump JA. Brucellosis in low-income and middle-income countries. Curr Opin Infect Dis. 2013; 26(5): 404-12. doi: 10.1097/QCO.0b013e3283638104. PMID: 23963260, PMCID: PMC3888775.

2) Parlak M, Guducuoglu H, Bayram Y, Cikman A, Aypak C, Kilic S, et al. Identification and determination of antibiotic susceptibilities of Brucella strains isolated from patients in van, Turkey by conventional and molecular methods. Int J Med Sci. 2013; 10(10): 1406-11. doi: 10.7150/ijms.6565. PMID: 23983603, PMCID: PMC3753419.

3) Piranfar V, Sharif M, Hashemi M, Vahdati AR, Mirnejad R. Detection and discrimination of two Brucella species by multiplex real-time PCR and high-resolution melt analysis curve from human blood and comparison of results using RFLP. Iran J Basic Med Sci. 2015; 18(9): 909-14. PMID: 26523223, PMCID: PMC4620191.

4) Russo G, Pasquali P, Nenova R, Alexandrov T, Ralchev S, Vullo V, et al. Reemergence of human and animal brucellosis, bulgaria. Emerging infectious diseases. 2009; 15(2): 314-6. PMID: 19193282, PMCID: PMC2657635.

5) Mirnejad R, Mohamadi M, Piranfar V, Mortazavi SM, Kachuei R. A duplex PCR for rapid and simultaneous detection of Brucella spp. in human blood samples. Asian Pac J Trop Med. 2013; 6(6): 453-6. doi: 10.1016/S1995-7645(13)60073-5. PMID: 23711705.

6) Gwida M, Al Dahouk S, Melzer F, Rosler U, Neubauer H, Tomaso H. Brucellosis - regionally emerging zoonotic disease? Croatian medical journal. 2010; 51(4): 289-95. PMID: 20718081, PMCID: PMC2931433.

7) Mirnejad R, Doust RH, Kachuei R, Mortazavi SM, Khoobdel M, Ahamadi A. Simultaneous detection and differentiates of Brucella abortus and Brucella melitensis by combinatorial PCR. Asian Pac J Trop Med. 2012; 5(1): 24-8. doi: 10.1016/S1995-7645(11)60239-3. PMID: 22182638.

8) Duvnjak S, Racic I, Spicic S, Zdelar-Tuk M, Reil I, Cvetnic Z. Characterisation of Brucella suis isolates from Southeast Europe by multi-locus variable-number tandem repeat analysis. Vet Microbiol. 2015; 180(1-2): 146-50. doi: 10.1016/j.vetmic.2015.08.013. PMID: 26324171.

9) Mohamed Zahidi J, Bee Yong T, Hashim R, Mohd Noor A, Hamzah SH, Ahmad N. Identification of Brucella spp. isolated from human brucellosis in Malaysia using high-resolution melt (HRM) analysis. Diagn Microbiol Infect Dis. 2015; 81(4): 227-33. doi: 10.1016/j.diagmicrobio.2014.12.012. PMID: 25641125.

10) Joint FAO/WHO expert committee on brucellosis. World Health Organ Tech Rep Ser. 1986; 740: 1-132. PMID: 3097967.

11) Ersoy Y, Sonmez E, Tevfik MR, But AD. Comparison of three different combination therapies in the treatment of human brucellosis. Tropical doctor. 2005; 35(4): 210-2. doi: 10.1258/004947505774938765. PMID: 16354469. 
12) Solera J, Rodriguez-Zapata M, Geijo P, Largo J, Paulino J, Saez L, et al. Doxycycline-rifampin versus doxycycline-streptomycin in treatment of human brucellosis due to Brucella melitensis. The GECMEI Group. Grupo de Estudio de Castilla-la Mancha de Enfermedades Infecciosas. Antimicrob Agents Chemother. 1995; 39(9): 2061-7. PMID: 8540716, PMCID: PMC162881.

13) Yousefi-Nooraie R, Mortaz-Hejri S, Mehrani M, Sadeghipour P. Antibiotics for treating human brucellosis. Cochrane Database Syst Rev. 2012; 10: CD007179. doi: 10.1002/14651858.CD007179.pub2. PMID: 23076931.

14) Ariza J, Bosilkovski M, Cascio A, Colmenero JD, Corbel MJ, Falagas ME, et al. Perspectives for the treatment of brucellosis in the 21st century: the Ioannina recommendations. PLoS medicine. 2007; 4(12): e317. doi: 10.1371/journal.pmed.0040317. PMID: 18162038, PMCID: PMC2222927.

15) Pappas G, Solera J, Akritidis N, Tsianos E. New approaches to the antibiotic treatment of brucellosis. Int J Antimicrob Agents. 2005; 26(2): 101-5. doi: 10.1016/j.ijantimicag.2005.06.001. PMID: 16039098.

16) Al-Mariri A, Safi M. The Antibacterial Activity of Selected Labiatae (Lamiaceae) Essential Oils against Brucella melitensis. Iran J med sci. 2013; 38(1): 44-50. PMID: 23645957, PMCID: PMC3642944.

17) Aliskan H, Can F, Demirbilek M, Colakoglu S, Kilic S, Arslan H. Determining in vitro synergistic activities of tigecycline with several other antibiotics against Brucella melitensis using checkerboard and time-kill assays. J chemother. 2009; 21(1): 24-30. doi: 10.1179/joc.2009.21.1.24. PMID: 19297268.

18) Mitterer G, Huber M, Leidinger E, Kirisits C, Lubitz W, Mueller MW, et al. Microarray-based identification of bacteria in clinical samples by solid-phase PCR amplification of 23S ribosomal DNA sequences. J Clin Microbiol. 2004; 42(3): 1048-57. PMID: 15004052, PMCID: PMCPMC356827.

19) Deyholos MK, Galbraith DW. High-density microarrays for gene expression analysis. Cytometry. 2001; 43(4): 229-38. doi: 10.1002/1097-0320(20010401)43:4<229::AID-CYTO1055>3.0.CO;2-2.

20) Mangalgi S, Sajjan A. Comparison of three blood culture techniques in the diagnosis of human brucellosis. J lab physicians. 2014; 6(1): 14-7. doi: 10.4103/0974-2727.129084. PMID: 24696554, PMCID: PMC3969635.

21) Jenkins SG, Schuetz AN. Current concepts in laboratory testing to guide antimicrobial therapy. Mayo Clin Proc. 2012; 87(3): 290-308. doi: 10.1016/j.mayocp.2012.01.007. PMID: 22386185, PMCID: PMC3496983.

22) Sekhavati MH, Heravi RM, Tahmoorespur M, Yousefi S, Abbassi-Daloii T, Akbari R. Cloning, molecular analysis and epitopics prediction of a new chaperone GroEL Brucella melitensis antigen. Iran J Basic Med Sci. 2015; 18(5): 499-505. PMID: 26124937, PMCID: PMC4475659.

23) Shaw WV, Packman LC, Burleigh BD, Dell A, Morris HR, Hartley BS. Primary structure of a chloramphenicol acetyltransferase specified by R plasmids. Nature. 1979; 282(5741): 870-2. PMID: 390404.

24) Roberts MC. Tetracycline resistance determinants: mechanisms of action, regulation of expression, genetic mobility, and distribution. FEMS Microbiol Rev. 1996; 19(1): 1-24. PMID: 8916553.

25) Roberts MC. Genetic mobility and distribution of tetracycline resistance determinants. Ciba Found symp. 1997; 207: 206-18; discussion 19-22. PMID: 9189643.

26) Labby KJ, Garneau-Tsodikova S. Strategies to overcome the action of aminoglycoside-modifying enzymes for treating resistant bacterial infections. Future med chem. 2013; 5(11): 1285-309. doi: 10.4155/fmc.13.80. PMID: 23859208, PMCID: PMC3819198.

27) Liang C, Xing B, Yang X, Fu Y, Feng Y, Zhang Y. Molecular epidemiology of aminoglycosides resistance on Klebsiella pneumonia in a hospital in China. Int J clin exp med. 2015; 8(1): 1381-5. PMID: 25785141, PMCID: PMC4358596.

28) Riccio ML, Docquier JD, Dell'Amico E, Luzzaro F, Amicosante G, Rossolini GM. Novel 3-Naminoglycoside acetyltransferase gene, aac(3)-Ic, from a Pseudomonas aeruginosa integron. Antimicrob Agents Chemother. 2003; 47(5): 1746-8. PMID: 12709352, PMCID: PMC153335.

29) Doi Y, Wachino J, Yamane K, Shibata N, Yagi T, Shibayama K, et al. Spread of novel aminoglycoside resistance gene aac(6')-Iad among Acinetobacter clinical isolates in Japan. Antimicrob Agents Chemother. 2004; 48(6): 2075-80. doi: 10.1128/AAC.48.6.2075-2080.2004. PMID: 15155202, PMCID: PMC415623.

30) Vakulenko SB, Donabedian SM, Voskresenskiy AM, Zervos MJ, Lerner SA, Chow JW. Multiplex PCR for detection of aminoglycoside resistance genes in enterococci. Antimicrob Agents Chemother. 2003; 47(4): 1423-6. PMID: 12654683, PMCID: PMC152526.

31) von Bargen K, Gagnaire A, Arce-Gorvel V, de Bovis B, Baudimont F, Chasson L, et al. Cervical Lymph Nodes as a Selective Niche for Brucella during Oral Infections. PLoS One. 2014; 10(4): e0121790. doi: 10.1371/journal.pone.0121790. PMID: 25919005, PMCID: PMC4412401. 
32) Halliday JE, Allan KJ, Ekwem D, Cleaveland S, Kazwala RR, Crump JA. Endemic zoonoses in the tropics: a public health problem hiding in plain sight. Vet rec. 2015; 176(9): 220-5. doi: 10.1136/vr.h798. PMID: 25722334, PMCID: PMC4350138.

33) Chacon-Diaz C, Altamirano-Silva P, Gonzalez-Espinoza G, Medina MC, Alfaro-Alarcon A, Bouza-Mora $\mathrm{L}$, et al. Brucella canis Is an Intracellular Pathogen That Induces a Lower Proinflammatory Response than Smooth Zoonotic Counterparts. Infect immun. 2015; 83(12): 4861-70. doi: 10.1128/IAI.00995-15. PMID: 26438796, PMCID: PMC4645416.

34) Bueno-Mari R, Almeida AP, Navarro JC. Editorial: Emerging Zoonoses: Eco-Epidemiology, Involved Mechanisms, and Public Health Implications. Front public health. 2015; 3: 157 . doi: 10.3389/fpubh.2015.00157. PMID: 26106592, PMCID: PMC4459090.

35) Soares Cde P, Teles JA, dos Santos AF, Silva SO, Cruz MV, da Silva-Junior FF. Prevalence of Brucella spp in humans. Rev Lat Am Enfermagem. 2015; 23(5): 919-26. doi: 10.1590/0104-1169.0350.2632. PMID: 26487143, PMCID: PMC4660415.

36) Behzadi P, Ranjbar R, Alavian SM. Nucleic Acid-Based Approaches for Detection of Viral Hepatitis. Jundishapur J Microbiol. 2015; 8(1). PMCID: PMC4350052.

37) Najafi A, Ram M, Ranjbar R. Microarray: Principles \& Applications. 1st ed. Tehran: Persian Science \& Research Publisher; 2012.

38) Behzadi P, Behzadi E, Ranjbar R. The application of Microarray in Medicine. ORL ro. 2014; 7(24).

39) Behzadi P, Behzadi E, Ranjbar R. Microarray Data Analysis. Alban Med J. 2014; 4: 84-90.

40) Mao B-H, Chang Y-F, Scaria J, Chang C-C, Chou L-W, Tien N, et al. Identification of Escherichia coli genes associated with urinary tract infections. J Clin Microbiol. 2012; 50(2): 449-56. doi: 10.1128/JCM.00640-11. PMID: 22075599, PMCID: PMC3264149.

41) Behzadi P, Behzadi E, Ranjbar R. Multidrug-Resistant Bacteria/Bacterii rezistente la mai multe antibiotice si chimioterapice. Infectio ro. 2014; (39): 29. 